\title{
The Development of Leisure Sports in Ancient China and Its Contemporary Sports Culture Value
}

\author{
Jianqiang Guo, Rong $\mathrm{Li}^{*}$ \\ School of Physical Education, Changzhou University, Changzhou, China \\ Email: ${ }^{*} 1 r @ c c z u . e d u . c n$
}

How to cite this paper: Guo, J. Q., \& Li, R. (2017). The Development of Leisure Sports in Ancient China and Its Contemporary Sports Culture Value. Advances in Physical Education, 7, 377-382.

https://doi.org/10.4236/ape.2017.74031

Received: August 18, 2017

Accepted: October 10, 2017

Published: October 13, 2017

Copyright $\odot 2017$ by authors and Scientific Research Publishing Inc. This work is licensed under the Creative Commons Attribution International License (CC BY 4.0).

http://creativecommons.org/licenses/by/4.0/

\begin{abstract}
The traditional culture not only influences the life of modern people, but also promotes the sports undertakings in China. Influenced by the traditional culture, the development of leisure sports in ancient China has very strong traditional cultural nature and its contemporary value connotation. This paper analyzes and discusses on the development of leisure sports in ancient China and its contemporary sports culture value, aiming at further making the development of leisure sports in ancient China and its cultural value connotation clearly, doing some beneficial researches and making some contributions.
\end{abstract}

\section{Keywords}

Leisure Sports, Sports Culture, Social Value, Traditional Culture

\section{Introduction}

The leisure sports in China have national features. There are not only folk festivals such as acrobatics and boat race for celebration, but also the swing to play every day, as well as Cuju and sumo with military nature in ancient times. From the end of the primitive society when sports came into being to now, there have already been sports for over 10,000 years (Zhang \& Pan, 2011). They develop and evolve constantly, integrating with traditional Chinese culture closely, which becomes an important content in the traditional culture, and influences the development of sports undertakings in future China greatly (Yao, 2009). This article studies the ancient leisure sports defined as the ancient nature of the entertainment with a variety of entertainment-oriented movement. For example, $\mathrm{Cu}$ ju, horse racing, rope skipping, polo, archery and so on. 


\section{The Origin and Development of Leisure Sports in Ancient China}

The ancient sports appeared very early, at the end of the primitive society at the earliest. Because of the extremely low level of productive forces of people at that time, people could only survive on vegetation, wild fruits and animal meat. Because of the very dangerous and poor living environment, the average age of the hominid was very low, and many people died before they grew into adults. Under such circumstances, the fundamental objective for human to be engaged in various activities was to be better to survive. Afterwards, there were wars between clans, and religious activities took place, so the hominid began to increase the contents of activities properly, and adjust certain skills in activities. In this way, some professional activities aiming at improving physical fitness of people and for recreation began to separate themselves from production, and the ancient sports came into being thereout. From another point of view, in spite of the very low level of productive forces in the primitive society and the frequent situation of insufficient foods, there were too many foods occasionally. When people saw the plentiful foods they obtained, their hearts were full of joy and excitement. At this time, people would express their excitement in the form of dance, which was recorded in the relevant historical data in detail. Thus it could be seen that, the sports with the nature of amusement in ancient China originated from such activities with both content of plot and certain sports (Yu \& Zou, 2005; Zhang, 2005).

\section{The Overview of the Development of Leisure Sports in Ancient China}

\subsection{The Overview of Folk Leisure Sports in China}

From the Qin and Han Dynasties to the Ming and Qing Dynasties, with the development of social economy, many folk festive games in China developed to be more and more prosperous. For example, after the Han and Tang Dynasties, there were activities of playing on a swing from place to place in the folk (Zhang, 2005; Luo \& Su, 2008).

In Sui and Tang dynasties, all emperors showed special preference to Cuju, and there were many emperors who disregarded the affairs of state because of Cuju. Strongly advocated by the ruling class, common people in the folk also began to participate in those sports activities with the nature of entertainment, and many sports gained a certain development at that time. The activities such as Weiqi and Cuju in the Tang Dynasty were also spread to some other Asian countries such as North Korea and Japan, and were further passed down in these countries (Zhang, 2005; Luo \& Su, 2008; Fang \& Yang, 2006). In areas for minorities such as Sinkiang, Tibet, Inner Mongolia and Yunnan, the sports activity of horse racing was very popular.

Kicking shuttlecock was a favorite game of many women and children in the Song Dynasty. After the Jin and Yuan Dynasties, the activity of stone ball was very popular in Yellow River Basin and Beijing. In ancient times, the Han natio- 
nality called rope skipping as "Tiaobaisuo". In Picture of Beneficial Games from the Qing Dynasty, there were also some records about the game of rope skipping. The short rope would be skipped by a single person or two people generally, while the long rope would be used for more people.

\subsection{The Overview of the Development of Leisure Sports among the Nobilities in China}

Wars often took place in the period of slave society. In order to guarantee their own ruling, the slave owner attached importance to the army building and soldier training specially. A kind of specific military sports-driving skill, i.e. driving, came into being during the period of Shang and Zhou Dynasties. In the Zhou Dynasty, shooting was a kind of important education in social morality among the dominators, with very normative etiquette procedure. In the meantime, shooting was also a kind of athletics with normative hierarchy. Up to the Spring and Autumn Period and Warring States Period, shooting by crossbow came into being. The sport of Tuho (a kind of cast game in ancient times) was very popular in the Jin Dynasty. This was a kind of games which literati and officialdom in ancient times loved specially when holding a banquet. In the banquet, people would take the wine pot instead of the target. Then, both the host and the guests would stand within a certain distance, taking turns to throw the arrow without arrowhead into the wine pot, with who threw the most into it as the winner. $\mathrm{Cu}$ ju, i.e. football, was a very popular sports activity of the royal court in ancient times. From the Qin and Han Dynasties, in order to train the soldiers, the dominator therefore advocated the football especially. In the Song Dynasty, royal nobilities especially loved football, so the competitiveness of Cuju in this period made a very great progress. The sport of polo came about in the Han Dynasty, called as "Jiju" or "playing a ball game" in ancient times. The sport of polo reached its golden age in the Tang Dynasty. At the end of the Qing Dynasty, the ruling class prohibited horse breeding in the folk in order to suppress people's revolt, and the sport of polo was interrupted from then on. The aulic sports at that time were mainly wrestling, hunting, riding and shooting, swing, board game and other various kinds of sports mainly for recreation and entertainment.

\section{The Social Origin of Declining Leisure Sports in Ancient China}

As we know, the leisure sports ran to peak in the Song Dynasty, and turned to decline little by little from then on. As for the reasons of such phenomenon, the hindering of social origin also couldn't be neglected, in addition to the cultural factors mentioned above.

\subsection{Prosperity of the Folk Vaudeville and Professional Performance}

With the development of society, the hierarchy of citizen began to emerge, and the demand in culture and entertainment also went up thereout, which stimu- 
lated the appearance of professional artists to a certain degree. Especially in cities, there were more such kind of professional artists, and places such as folk art performance venues even appeared in cities for entertainment. People could enjoy diverse performance activities in such venues, not only including entertainment programs such as acrobatics, talking and singing, but also leisure sports such as weightlifting and sumo. These recreational activities gained development to some extent, but the performers of these activities were better at performance, resulting in not high degree of public participation. Therefore, only very few artists could perform, which made many recreational activities decline little by little, or even die out.

\subsection{Emerging Creation of Social Literature, Art and Novel}

The traditional Chinese opera appeared with the development of small-scale feudal peasant economy. Just because of the unique small-scale peasant economy in the feudal society, the development of traditional Chinese opera and poetic drama was stimulated. In addition, novels also developed to a different extent. The form of literary works didn't change greatly, with their contents closely linked to the feudal thought. Therefore, in the ancient Chinese culture, the traditional Chinese opera became an important component, particularly eye-catching, and the market of leisure sports was also divided up by the poetic drama and novel by more than half. In a word, the Neo-Confucianism reached its golden age in the Song Dynasty, and the folk art performance venues flourished unprecedentedly. In such social background, leisure sports were hindered to a certain extent, very difficult to develop greatly. We had to say that, the leisure sports in China were very difficult to survive between the cracks, so decline also became an inevitable trend (Chen, 2010; Zhou \& Xue, 2001).

\subsection{Influence of the Change of Dynasties and the Policy of Ruling Class}

In feudal society, the ordinary people paid more attention to the interests of nobilities, and they often followed the example of them, with the development of sports as a very typical example. If a certain leisure sports activity was stressed and loved by nobilities, especially by royal nobilities, they would be chased after by people, and would be thus carried out in the folk within a large area. As for those sporting events not stressed or even rejected by royal nobilities, they would decline quickly or disappear. Many sporting events were greatly destroyed in the change of dynasties for thousands of years, and declined little by little (Chen, 2010; Zhou \& Xue, 2001; Peng \& Xiao, 2008). The gradual decline of very popular sporting events in ancient time such as polo and Cuju could prove it.

\section{The Significance of Contemporary Sports Cultural Value for the Leisure Sports in Ancient China}

As a kind of famous cultural inheritance, the traditional sports in China also experienced social development and change, but they still didn't lose their pure 
cultural connotations and kept relatively stable ancient cultural characteristics. After the founding of new China, the protection of many traditional sports was paid high attention to. However, because of the low social and economic development level at that time, the basis of folk sports was very weak, difficult to effectively create the good development condition for the development of traditional culture and sports really, which was deeply regretted by many men of insight.

\subsection{The Traditional Sporting Events Witness the Track of Human Civilization Development}

The traditional sport is closely linked to various folk cultures. It has two functions, one is to inherit the folk culture, and the other is to do physical exercise. To inherit the folk culture is the more important function between them. Through the investigation and research on traditional sports, the cultural researchers can trace the origin and development history of folk culture.

\subsection{The Traditional Sports Reflect and Collect the Thought Essence of Chinese Culture}

As the birthplace of Wushu, China is already well-known all over the world nowadays for shadowboxing, Shaolin Kung fu and so on. Wushu is not a pure sports activity any longer, and its greater value lies in its cultural value. Wushu is just one of the traditional Chinese sports culture. We can see the sports form covered in the traditional sports culture through Wushu, such as modesty, toleration, calmness and honesty. In addition, Wushu pays attention to not only doing physical exercises, but also doing exercises in breath and heart, and finally achieves the objectives of body building and self-cultivation. The contents inherited by Wushu culture are very rich and colorful, including footwork, technique and so on; Wushu secret book, etiquette, taboo and so on; various ideas (Peng \& Xiao, 2008; Wang \& Li, 2006).

\subsection{The Spiritual Connotation and Traits Endowed by the Traditional Sports to Modern Sports}

With the progress of the times, all kinds of traditional sports activities are innovated and enriched constantly, and become eye-catching whether in the forms or in the contents. In recent years, traditional sports activities also gain great development, and many modern sporting events are achieved. Modern art and modern sports are based on the development of traditional sports, not only to retain the traditional sports folklore characteristics, but also increased the fun, rich its content, and even some sports activities have to the world. The traditional sports activities contain very great cultural value, which can provide the modern sports and modern art with endless development space (Wang \& Li, 2006). However, we can't change the charm of traditional sports because of interests, but shall keep its internal cultural value well. 


\section{Conclusion}

During the development process of Chinese civilization for thousands of years, the sports once played an important role in ancient times. However, influenced by some cultural factors and social factors, many ancient leisure sporting events declined or even failed to be handed down. Although some leisure sporting events are inherited, their states of development are also worrisome. In order to further protect the leisure sports in ancient China and make it inherited better, we shall carry out in-depth study on leisure sports, and try our best to promote the development of leisure sports.

\section{Acknowledgements}

Jiangsu Higher Education Teaching Reform Research Project. Item number: 2015JSJG108.

\section{References}

Chen, X. D. (2010). Discussion on the Development of Leisure Sports in Colleges and Universities. The Guide of Science \& Education, No. 11, 36-37.

Fang, X. P., \& Yang, Y. H. (2006). The View of Research Status and Tendency of Leisure Sports in Our Country from Bibliometrics. Journal of Anhui University of Science and Technology (Natural Science Edition), 21, 74-76.

Luo, J. P., \& Su, X. (2008). Discussion on the Development and Evolution of Leisure Sports under Different Cultural Backgrounds. Science and Technology Innovation Herald, No. $20,161+163$.

Peng, C., \& Xiao, J. (2008). The Current Situation of and Analysis on Leisure Sports in Our Country. Journal of Xiangtan Normal University (Natural Science Edition), 30, 164-166.

Wang, B., \& Li, X. (2006). Modern Leisure Sports under the View of Cultural Value. Sports World (Academic Edition), No. 1, 3-5.

Yao, Z. (2009). Discussion of Sports Exhibition on the Development of Leisure Sports. Consumption Guide, 9, 18-19.

Yu, W. Q., \& Zou, Y. H. (2005). Thoughts on the Humanistic Development of Leisure Sports. Sports Culture Guide, No. 9, 39-41.

Zhang, Y. (2005). Discussion on the Characteristics of Times of the Development and Evolution of Leisure Sports in China. Journal of Shaoyang University (Natural Science Edition), No. 4, 111-113.

Zhang, Z. J., \& Pan, S. L. (2011). Investigation on the Leisure Sports Culture in Ancient China. Everyone, 136, 128-129.

Zhou, H. B., \& Xue, H. W. (2001). Leisure Sports, Public Physical Training \& Social Development. Liaoning Sport Science and Technology, No. 3, 70. 